\title{
FIBROUS DYSPLASIA OF THE ORBITAL BONES*
}

\author{
BY \\ ALY MORTADA \\ Department of Ophthalmology, Faculty of Medicine, Cairo University, Egypt
}

\begin{abstract}
A NUMBER of bone diseases may affect the orbital bones decreasing the orbital volume and narrowing the optic canal, giving rise to unilateral exophthalmos and usually optic atrophy, simulating clinically an orbital tumour. Among such diseases are osteitis deformans (Paget, 1876); leontiasis ossea (Virchow, 1896); osteopetrosis (Albers-Schönberg, 1904), and the generalized and localized osteitis fibrosa cystica described by von Recklinghausen.

Albright, Butler, Hampton, and Smith (1937) classified the localized osteitis fibrosa lesions as solitary and disseminated according to the number of bones affected. For these two forms, Lichtenstein (1938) introduced the terms monostotic and polyostotic fibrous dysplasia of bone.
\end{abstract}

Fibrous dysplasia of bone differs from generalized osteitis fibrosa cystica. Clinically it appears about the age of 10 years, is usually attributed to trauma, and becomes stationary after a limited period of active bony changes in a limited area. The aetiology of the disease is unknown, but it is probably a developmental mesodermal disorder. The blood calcium, phosphorus, and plasma phosphatase are normal. There is no hyperparathyroidism. Histopathologically the disease is characterized by the way in which the medullary cavity of the affected bones is filled by fibrous tissue in which spicules of calcified bone may be developed and small islands of hyaline cartilage may sometimes appear. As a consequence, there is widening of the affected bones with thinning of their cortex and replacement of cancellous bone and marrow by solid fibrous tissue (Duke-Elder, 1952). Cyst formation may be present but osteoclastoma has not been recorded. $X$-ray examination shows the affected bone to be expanded and trabeculated; some areas are thick while others are porous. This picture differs from that of osteitis deformans, leontiasis ossea, osteopetrosis, metastasis, and osteogenic sarcoma of orbital bones, orbital osteoma, and sphenoidal ridge meningeoma. Polyostotic fibrous bone dysplasia, with sexual precocity (mostly in females), and patchy cutaneous pigmentation constitute Albright's syndrome.

Few cases of fibrous dysplasia of the orbital bones are recorded in the literature, so that the description of a new case is still of interest. 


\section{Case Report}

A 32-year-old female (Fig. 1) complained of slow proptosis and deterioration of vision in the left eye since the age of 10 years. There was no history of trauma, and the family history was not significant. There was no skin pigmentation or endocrine disorder. The height, weight, and general development were normal.

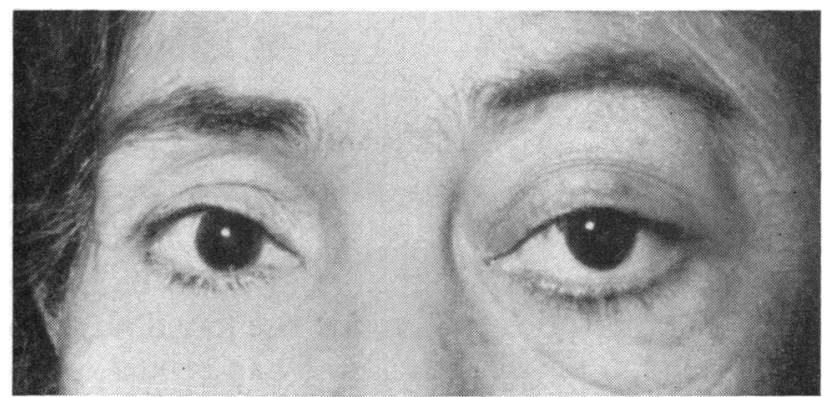

FIG. 1.-A case of fibrous dysplasia of the left orbital bones in a female aged 32, showing proptosis, and frontal, malar, and maxillary eminence.

Prominence of the frontal, malar, and maxillary bones on the left side gave an appearance of facial asymmetry.

The right eye was normal, with visual acuity $6 / 9$ and normal fundus and field of vision.

The left eye showed oedema of the eyelids, a forward proptosis of $25 \mathrm{~mm}$. (right $16 \mathrm{~mm}$.), and slight limitation of the ocular movements in all directions. The left fundus showed post-papilloedemic optic atrophy. The visual acuity was hand movements. No orbital tumour was palpable.

The blood count, calcium, phosphorus, and plasma phosphates were normal. The Wassermann reaction and tuberculin tests were negative.

A postero-anterior $X$ ray of the skull (Fig. 2) showed the characteristic radiographic appearances of fibrous dysplasia in the left orbital bones. There was definite thickening and expansion of the bones, areas of increased density being interspersed with porotic areas involving the lower parts of the frontal bone including the roof of the orbit, the greater wing of the sphenoid, malar, and upper part of the maxilla. The lesser wing of the sphenoid also showed expansion, thickening, and haziness of its upper border, and encroachment upon the superior orbital fissure.

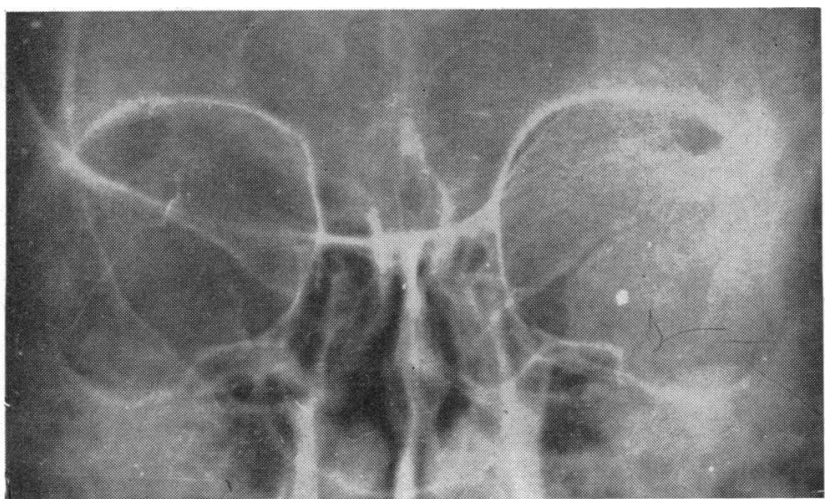

Fig. 2.-Postero-anterior $x$ ray view of skull, showing expansion and irregular thickening of lesser and greater wings of the sphenoid, the lower part of the frontal and malar, and the upper part of the maxillary bones in the left orbit. 
Oblique $x$-ray views showed a slight narrowing of the left optic canal. Lateral $x$ rays of the skull showed thickening and expansion of the roof of the orbit extending backwards to but not involving the pituitary fossa. $X$ rays of other parts of the skeleton showed no abnormality.

Orbital exploration did not reveal the presence of an orbital tumour.

A small portion of the surface of the affected malar bone was submitted for histopathological examination, and the normal bone structure was found to have been replaced by delicate fibrous tissue (Fig. 3) characteristic for fibrous dysplasia of bone.

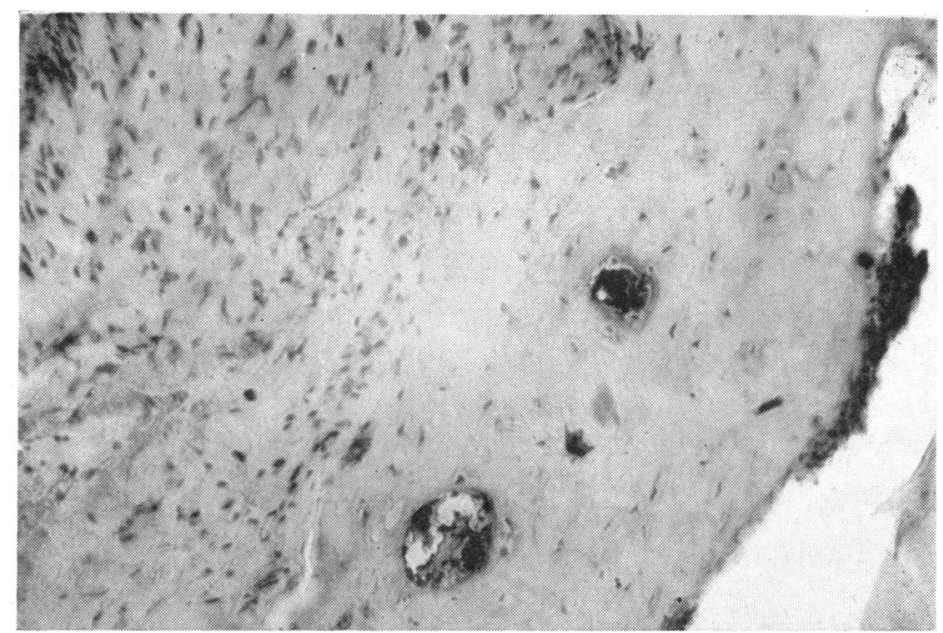

Fig. 3.-Cellular fibrous tissue replacing the bone, in a case of fibrous dysplasia of the orbital bones. $\times 120$.

\section{Discussion}

The cases of fibrous dysplasia affecting the orbital bones which have been reported in the literature can be classified into four groups:

(1) Cases with external signs of unilateral disease of the orbital bones without involvement of other bones. Chartres (1953) reported a case in which the left orbit was affected in a woman aged 21. Hobbs (1955) described a case in a girl aged 12 and one in a man aged 43. Matson (1958) described a case of unilateral progressive proptosis of $3 \frac{1}{2}$ years' duration with papilloedema in a 12-year-old boy, which was caused by fibrous dysplasia of the orbital bones; transfrontal decompression of the orbit and optic canal brought about a subsidence of papilloedema and improvement of visual acuity.

(2) Cases with external signs of unilateral disease of the orbital bones with involvement of other bones. Webb (1948) described a case of polyostotic fibrous dysplasia affecting the left frontal bone with displacement downwards of the orbit and involvement of the humerus, ulna, and femur.

(3) Cases without external signs of disease of the orbital bones but presenting with optic atrophy caused by the involvement of the optic canals. Weygand, Craig, and Rucker (1952) reported an interesting case of a boy aged 
12, with no external signs, but optic atrophy of the right eye; $X$-ray examination showed a tumour arising anterior to the sella turcica, and craniotomy showed a large tumour of the body of the sphenoid bone extending into the roofs of the optic canals compressing the chiasma. Histopathological examination of the excised tumour showed the typical changes of fibrous dysplasia of bone.

(4) Cases with Albright's syndrome. Falconer and Cope (1942) described a boy aged 11 with optic atrophy of the left eye, who showed fibrous dysplasia of the left orbital bones and both femora. A second patient had bilateral optic atrophy due to fibrous dysplasia of the skull, marked at the base, which caused a bony swelling anterior to the sella turcica and affected the chiasma.

\section{Summary}

The few cases of fibrous dysplasia of the orbital bones reported in the literature may be classified into four groups:

(1) External signs of unilateral bony orbital disease without involvement of other bones.

(2) External signs of unilateral bony orbital disease with involvement of other bones.

(3) No external signs of bony orbital disease but optic atrophy.

(4) Albright's syndrome.

The case here reported belongs to the first group, presenting the commoner manifestations of skull involvement: unilateral involvement of the orbital bones with proptosis and optic atrophy, confirmed by $x$ ray of the skull, and histopathological examination of the affected bone.

This is the first case of fibrous dysplasia of the orbital bones to be reported from Egypt.

\section{REFERENCES}

Albers-Schönberg, H. E. (1904). Münch. med. Wschr., 51, 365.

Albright, F., Butler, A. M., Hampton, A. O., and Smith, P. (1937). New Engl. J. Med., 216, 727.

Chartres, J. C. (1953). Brit. J. Radiol., 26, 104.

DuKE-ElDER, S. (1952). "Text-Book of Ophthalmology", vol. 5, p. 4754. Kimpton, London.

FAlConer, M. A., and Cope, C. L. (1942). Quart. J. Med., n.s. 11, 121.

HoвBs, H. E. (1955). "XVII Concilium Ophthalmologicum, 1954. Canada, U.S.A. Acta”, vol. 3, p. 1756.

Lichtenstein, L. (1938). Arch. Surg. (Chicago), 36, 874.

MATSON, D. D. (1958). Clin. Neurosurg., 5, 116.

PAGET, J. (1876). Lancet, 2, 714.

VIRCHOW, R. (1896). "Patologie des tumeurs."

Webi, J. R. D. (1948). Proc. roy. Soc. Med., 42, 557.

Weyand R. D., Craig, W. M., and Rucker, C. W. (1952). Proc. Mayo. Clin., $27,505$. 